\title{
Kinetics and Mechanistic Approach to the Benzimidazolium Fluorochromate Oxidation of Indole-2-aldehyde in Various Percentages of Acetic Acid and Water Mixture
}

\author{
V. SALEEM MALIK ${ }^{1}$, I. VANNAMUTHU ${ }^{1,2}$, S. SYED SHAFI ${ }^{3}$ and S. SHEIK MANSOOR ${ }^{1 *}$ \\ 1Department of Chemistry, C. Abdul Hakeem College (Autonomous), Melvisharam - 632 509, India. \\ ${ }^{2}$ Department of Chemistry, Periyar Government Arts College, Cuddalore - 607 001, India. \\ ${ }^{3}$ Department of Chemistry, Thiruvalluvar University, Serkadu, Vellore - 632 106, India. \\ ${ }^{*}$ Corresponding author E-mail: smansoors2000@yahoo.co.in
} http://dx.doi.org/10.13005/ojc/310108

(Received: November 25, 2014; Accepted: January 08, 2015)

\begin{abstract}
The kinetics of benzimidazolium fluorochromate (BIFC) catalysed oxidation of indole-2aldehyde $(2-\operatorname{In} \mathrm{A})$ with perchloric acid in $50 \%$ acetic acid- $50 \%$ water solvent mixture at $303 \mathrm{~K}$ has been followed spectrophotometrically. The reaction is first order with respect to [BIFC], [2-InA] and $\left[\mathrm{H}^{+}\right]$and the reaction is catalyzed by hydrogen ions. A suitable mechanism has been proposed.
\end{abstract}

Key words: Indole-2-aldehyde, benzimidazolium fluorochromate, oxidation, kinetics

\section{INTRODUCTION}

Oxidation of aldehydes into the corresponding carboxylic acids is one of the important methods in organic synthesis as the carboxylic acids are versatile intermediates in a variety of synthetic transformations ${ }^{1}$. Numerous reagents and experimental procedures have been developed to carry out this kinetic transformation, in particular, reagents containing $\mathrm{Cr}(\mathrm{VI})$ reactive species are widely used for the oxidation of aldehydes to carboxylic acids ${ }^{2-7}$. Over a few decades the researchers have continuously developed and modified the reagents. Many attempts have been made to develop nitrogen containing heterocyclic $\mathrm{Cr}(\mathrm{VI})$ complexes ${ }^{8-11}$.

A series of indole-2-carboxylic acid benzylidene-hydrazides has been identified as a new class of potent apoptosis inducers through a novel cell-based caspase HTS assay ${ }^{12}$. A search of literature revealed that only few reports are available for kinetics of oxidation of heterocyclic aldehydes ${ }^{13-16}$.

Benzimidazolium fluorochromate ${ }^{17-20}$ was reported as a mild, stable and selective oxidant. BIFC has been reported as an effective oxidant for the oxidation of alcohols ${ }^{17,18}$, benzaldehydes ${ }^{19}$ and 
anilines $^{20}$.We have been interested in the kinetic and mechanistic aspects of the oxidation by complexed $\mathrm{Cr}(\mathrm{VI})$ species, and several studies on halochromates have already been reported ${ }^{19-22}$. In continuation of our earlier work, we now report the kinetics of oxidation of indole-2-aldehyde by BIFC in acetic acid water medium in various solvent compositions and to determine thermodynamic parameters. A probable mechanism has been proposed.

\section{EXPERIMENTAL}

\section{Materials}

Benzimidazole and chromium trioxide were obtained from Fluka (Buchs, Switzerland). The heterocyclic aldehyde used was indole-2-aldehyde. BIFC was prepared by reported method ${ }^{17}$ and its purity is checked by an iodometric method. Acetic acid was purified by standard method and the fraction distilling at $118{ }^{\circ} \mathrm{C}$ was collected.

\section{Kinetic measurements}

The kinetic studies were carried out in $50 \%$ acetic acid - 50\% water $(\mathrm{v} / \mathrm{v})$ at constant temperatures $( \pm 0.01 \mathrm{~K})$, under pseudo first-order conditions ( $[2-\operatorname{In} A]>[B I F C]$ ) using a Shimadzu UV1800 UV-Vis spectrophotometer. Reaction mixtures for kinetic runs were prepared by quickly mixing the solutions of the 2-InA and BIFC in varying volumes so that in each run the total volume was $5 \mathrm{ml}$. The progress of the reaction was monitored by following the disappearance of BIFC at $368 \mathrm{~nm}$. The pseudofirst-order rate constant $\mathrm{k}_{\text {obs }}$, was evaluated from the linear ( $r=0.990$ to 0.999$)$ plots of log [BIFC] against time for up to $80 \%$ reaction. The second order rate constant $k_{2}$, was obtained from the relation $k_{2}=k_{\text {obs }}$ / [Substrate].

\section{Product analysis}

Product analysis was carried out under kinetic conditions i.e., with excess of the substrate over BIFC. In a typical experiment, indole-2aldehyde $(0.1 \mathrm{~mol})$, perchloric acid $(0.32 \mathrm{~mol})$ and BIFC (0.01 mol) were dissolved in acetic acid - water mixture (50 \% - 50\%) and the solution was allows to stand in the dark for about $48 \mathrm{~h}$ to ensure completion of the reaction. The reaction mixture was then evaporated and extracted with ether. The ether layer was washed with water many times. The ether layer was then kept on a water bath for the evaporation of ether and cooled in ice bath to obtain the product (m.p. $203-205^{\circ} \mathrm{C}$; Lit. m.p. $202-206$ $\left.{ }^{\circ} \mathrm{C}\right)$. The product was dissolved in benzene and a careful TLC analysis was done with picolinic acid (indole-2-carboxylic acid) as reference. Only one spot corresponding to indole-2-carboxylic acid was obtained. Formation of indole-2-carboxylic acid was further confirmed by mixing the product with pure indole-2-carboxylic acid and noting that there was no change in the melting point. MS (ESI): $\mathrm{m} / \mathrm{z} 162$ $(\mathrm{M}+\mathrm{H})^{+}$. Anal. Calcd. for $\mathrm{C}_{9} \mathrm{H}_{7} \mathrm{NO}(\%)$ : C, 67.07; $\mathrm{H}$, 4.38; N, 8.69. Found: C, 67.00; H, 4.31; N, 8.59.

\section{Stoichiometric studies}

Stoichiometric analysis showed that $3 \mathrm{~mol}$ of indole-2-aldehyde consumed $2 \mathrm{~mol}$ of BIFC in accordance with Eq (1) to give indole-2-carboxylic acid.

$3 \mathrm{C}_{9} \mathrm{H}_{7} \mathrm{NO}+2 \mathrm{Cr}(\mathrm{VI})+3 \mathrm{H}_{2} \mathrm{O} \rightarrow 3 \mathrm{C}_{9} \mathrm{H}_{7} \mathrm{NO}_{2}+2 \mathrm{Cr}$ (III) $+6 \mathrm{H}^{+}$

(Indole-2-aldehyde)

\section{RESULTS AND DISCUSSION}

\section{Dependence on [BIFC]}

Under the experimental conditions, [2-InA] $>>[B I F C)]$, the rate of disappearance of BIFC shows a first order dependence on [BIFC]. The concentration of BIFC was varied in the range of $0.5 \times 10^{-3}$ to $2.5 \times 10^{-3} \mathrm{~mol} \mathrm{dm}^{-1}$ at constant [2-InA], $\left[\mathrm{H}^{+}\right]$at $303 \mathrm{~K}$ and the rates were measured (Table $1)$. The near constancy in the value of $k_{\text {obs }}$ irrespective of the concentration confirms the first order dependence on BIFC.

\section{Dependence on [2-InA]}

The order of the reaction with respect to [2$\ln \mathrm{A}]$ is unity, $k_{1}$ is directly proportional to [2-InA] as evident from the constant values of $k_{2}$ (Table 1). Plots of $\log k_{1} V s \log [2-\ln \mathrm{A}]$ are also linear with a slope value of 0.98 (Fig. 1). Under pseudo-first-order conditions, the plot of $k_{\text {obs }}$ versus [2-InA] is linear passing through origin (Fig.2). These results confirm the first-order nature of the reaction with respect to [2-InA].

\section{Dependence on $\left[\mathrm{H}^{+}\right]$}

The reaction is catalysed by perchloric acid. When the concentration of perchloric acid 
increased from 0.16 to $0.48 \mathrm{~mol} \mathrm{dm}^{-1}$ keeping all other reactant concentration as constant at $303 \mathrm{~K}$, $\mathrm{k}_{1}$ increases from $2.60 \times 10^{-4}$ to $8.22 \times 10^{-4} \mathrm{~s}^{-1}$ (Table $1)$. The plot of $\log k_{\text {obs }}$ versus $\log \left[\mathrm{H}^{+}\right]$is a straight line with the slope of 1.04 for $2-\ln A$. Therefore, order with respect to $\mathrm{H}^{+}$is one for $2-\operatorname{InA}$. BIFC may become protonated in the presence of acid and the protonated BIFC may function as an effective oxidant.

\section{Effect of solvent polarity on reaction rate}

The oxidation of 2- InA has been studied in the binary mixture of acetic acid and water as the solvent medium. The effect from solvent composition

Table 1: Effect of variation of [2-InA], [BIFC] and $\left[\mathrm{H}^{+}\right]$on the rate of the reaction at $303 \mathrm{~K}^{\mathrm{a}, \mathrm{b}}$

\begin{tabular}{|c|c|c|c|c|}
\hline $\begin{array}{l}10^{3}[\mathrm{BIFC}] \\
\left(\mathrm{mol} \mathrm{dm}^{-3}\right)\end{array}$ & $\begin{array}{l}10^{2}[2-\ln \mathrm{A}] \\
\left(\mathrm{mol} \mathrm{dm}{ }^{-3}\right)\end{array}$ & $\begin{array}{c}{\left[\mathrm{H}^{+}\right]} \\
\left(\mathrm{mol} \mathrm{dm}{ }^{-3}\right)\end{array}$ & $\begin{array}{c}10^{4} \mathrm{k}_{1}^{\mathrm{b}} \\
\left(\mathrm{s}^{-1}\right)\end{array}$ & $\begin{array}{c}10^{2} \mathrm{k}_{2}^{\mathrm{c}} \\
\left(\mathrm{dm}^{3} \mathrm{~mol}^{-1} \mathrm{~s}^{-1}\right)\end{array}$ \\
\hline 0.5 & 2.0 & 0.32 & 5.38 & 2.69 \\
\hline 1.0 & 2.0 & 0.32 & 5.44 & 2.72 \\
\hline 1.5 & 2.0 & 0.32 & 5.48 & 2.74 \\
\hline 2.0 & 2.0 & 0.32 & 5.42 & 2.71 \\
\hline 2.5 & 2.0 & 0.32 & 5.40 & 2.70 \\
\hline 1.0 & 1.0 & 0.32 & 2.78 & 2.78 \\
\hline 1.0 & 1.5 & 0.32 & 3.87 & 2.58 \\
\hline 1.0 & 2.5 & 0.32 & 6.90 & 2.76 \\
\hline 1.0 & 3.0 & 0.32 & 8.01 & 2.67 \\
\hline 1.0 & 2.0 & 0.16 & 2.60 & 0.16 \\
\hline 1.0 & 2.0 & 0.24 & 4.12 & 0.17 \\
\hline 1.0 & 2.0 & 0.40 & 6.74 & 0.17 \\
\hline 1.0 & 2.0 & 0.48 & 8.22 & 0.17 \\
\hline 1.0 & 2.0 & 0.32 & 5.34 & $2.67^{d}$ \\
\hline
\end{tabular}

${ }^{a}$ As determined by spectrophotometrically following the disappearance of $\mathrm{Cr}(\mathrm{VI})$ at 368 $\mathrm{nm}$; the error quoted in $\mathrm{k}$ values is the $95 \%$ confidence limit of 'Student $\mathrm{t}$ test'. ${ }^{b}$ Estimated from pseudo first order plots over $80 \%$ reaction.

'Individual $\mathrm{k}_{2}$ values estimated as $\mathrm{k}_{1} /[2-\ln \mathrm{A}]$ or $\mathrm{k}_{1} /\left[\mathrm{H}^{+}\right]$

${ }^{\mathrm{d} C}$ Contained $0.001 \mathrm{~mol} \mathrm{dm}^{-3}$ acrylonitrile

Solvent Composition $=50 \% \mathrm{AcOH}-50 \% \mathrm{H}_{2} \mathrm{O}(\mathrm{v} / \mathrm{v})$

Table 2: Pseudo-first order rate constants for the oxidation of indole-2-aldehyde by BIFC at various percentage of acetic acid-water medium at various temperatures

\begin{tabular}{|c|c|c|c|c|c|}
\hline \multirow{2}{*}{$\begin{array}{l}\% A c O H- \\
\mathrm{H}_{2} \mathrm{O} \\
(\mathrm{v} / \mathrm{v})\end{array}$} & \multirow{2}{*}{$\begin{array}{c}\text { Dielectric } \\
\text { constant }\end{array}$} & \multicolumn{4}{|c|}{$10^{4} k_{1} \quad\left(\mathrm{~s}^{-1}\right)$} \\
\hline & & $298 \mathrm{~K}$ & $303 \mathrm{~K}$ & $308 \mathrm{~K}$ & $313 \mathrm{~K}$ \\
\hline $30-70$ & 72.0 & 2.80 & 3.76 & 4.96 & 6.70 \\
\hline $40-60$ & 63.3 & 3.42 & 4.52 & 6.06 & 8.22 \\
\hline $50-50$ & 56.0 & 3.90 & 5.44 & 6.80 & 9.34 \\
\hline $60-40$ & 45.5 & 4.92 & 6.78 & 9.14 & 12.40 \\
\hline $70-30$ & 38.5 & 5.96 & 8.04 & 10.66 & 14.04 \\
\hline
\end{tabular}

$10^{2}[2-\operatorname{InA}]=2.0 \mathrm{~mol} \mathrm{dm}^{*} ; 10^{3}[\mathrm{BIFC}]=1.0 \mathrm{~mol} \mathrm{dm}^{-3} ; 10\left[\mathrm{H}^{+}\right]=3.2 \mathrm{~mol} \mathrm{dm}^{-3}$ 
Table 3: Second order rate constants and activation parameters for the oxidation of indole-2-aldehyde by BIFC at various percentage of acetic acid-water medium

\begin{tabular}{|c|c|c|c|c|c|c|c|c|}
\hline \multirow{2}{*}{$\begin{array}{l}\text { \%AcOH - } \\
\mathrm{H}_{2} \mathrm{O} \\
\text { (v/v) }\end{array}$} & \multicolumn{4}{|c|}{$10^{2} \mathrm{k}_{2}\left(\mathrm{dm}^{3} \mathrm{~mol}^{-1} \mathrm{~s}^{-1}\right)$} & \multirow{2}{*}{$\begin{array}{c}E_{a} \\
\left(\mathrm{JK} \mathrm{mol}^{-1}\right)\end{array}$} & \multirow{2}{*}{$\begin{array}{c}-\Delta S \# \\
\left(\mathrm{JK}^{-1} \mathrm{~mol}^{-1}\right)\end{array}$} & \multirow{2}{*}{$\begin{array}{c}\Delta \mathrm{H} \# \\
\left(\mathrm{JK}^{-1} \mathrm{~mol}^{-1}\right)\end{array}$} & \multirow{2}{*}{$\begin{array}{c}\Delta \mathrm{G} \# \\
\left(\mathrm{JK}^{-1} \mathrm{~mol}^{-1}\right) \\
(\text { at } 303 \mathrm{~K})\end{array}$} \\
\hline & $298 \mathrm{~K}$ & $303 \mathrm{~K}$ & $308 \mathrm{~K}$ & $313 \mathrm{~K}$ & & & & \\
\hline $30-70$ & 1.40 & 1.88 & 2.48 & 3.35 & 44.99 & $138.02 \pm 2.4$ & $42.12 \pm 0.8$ & $83.94 \pm 1.6$ \\
\hline $40-60$ & 1.71 & 2.26 & 3.03 & 4.11 & 45.56 & $134.76 \pm 3.6$ & $42.88 \pm 1.2$ & $83.71 \pm 2.4$ \\
\hline $50-50$ & 1.95 & 2.72 & 3.40 & 4.67 & 44.23 & $136.49 \pm 4.2$ & $41.36 \pm 1.4$ & $82.72 \pm 2.6$ \\
\hline $60-40$ & 2.46 & 3.39 & 4.57 & 6.20 & 47.86 & $123.86 \pm 1.2$ & $45.18 \pm 0.4$ & $82.71 \pm 0.8$ \\
\hline $70-30$ & 2.98 & 4.02 & 5.33 & 7.02 & 43.84 & $132.28 \pm 0.6$ & $40.21 \pm 0.2$ & $80.29 \pm 0.4$ \\
\hline
\end{tabular}

$10^{2}[2-\operatorname{InA}]=2.0 \mathrm{~mol} \mathrm{dm}^{-} ; 10^{3}[\mathrm{BIFC}]=1.0 \mathrm{~mol} \mathrm{dm}^{-3} ; 10\left[\mathrm{H}^{+}\right]=3.2 \mathrm{~mol} \mathrm{dm}^{-3}$

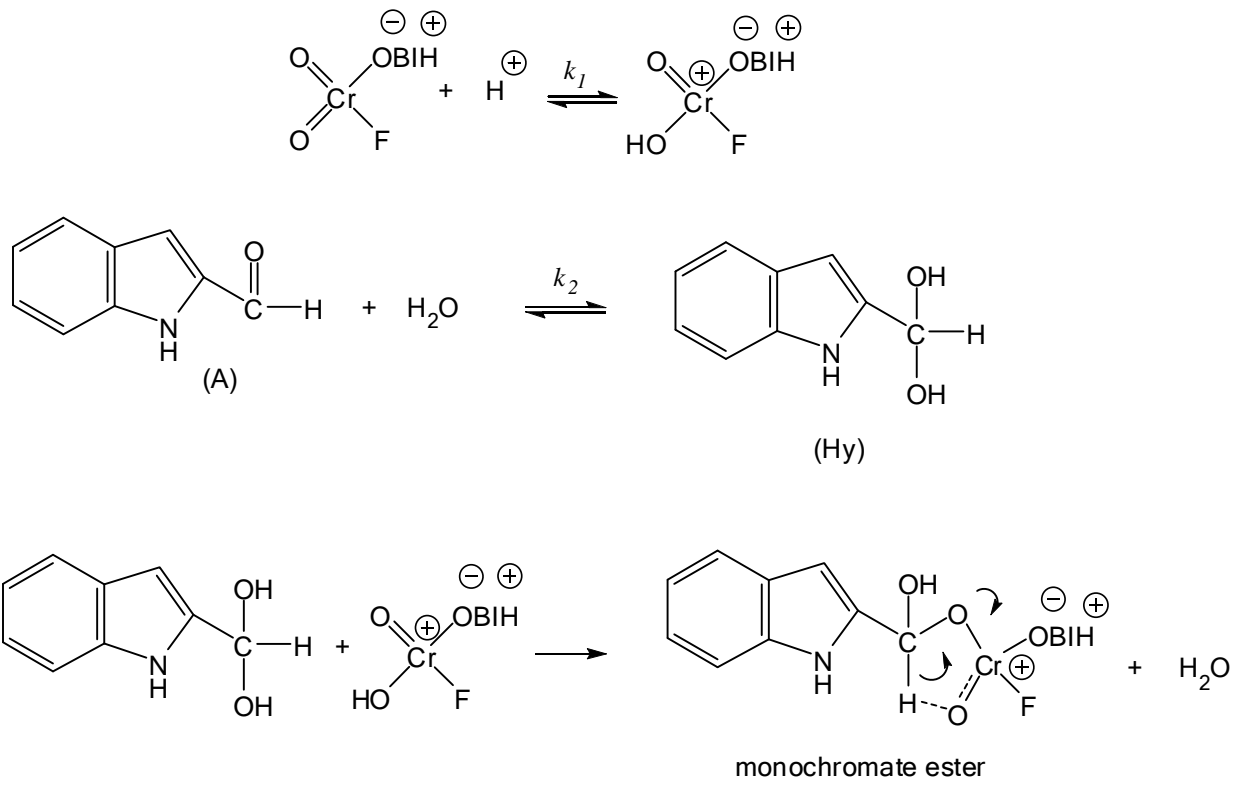

(E)

$$
\operatorname{Cr}(\mathrm{IV})+\operatorname{Cr}(\mathrm{VI}) \stackrel{\text { fast }}{\longrightarrow} 2 \mathrm{Cr}(\mathrm{V})+\operatorname{Substrate} \stackrel{\text { fast }}{\longrightarrow} \operatorname{Product}+\operatorname{Cr}(\mathrm{III})
$$


on the reaction rate was studied by varying the concentration of acetic acid from $30 \%$ to $70 \%$. For the oxidation of $2-\ln A$, the reaction rate increased remarkably with the increase in the proportion of acetic acid in the solvent medium. These results are presented in Table 2. The plot of log $k_{1}$ versus $1 /$ $\mathrm{D}$ (dielectric constant) is linear with positive slope suggesting the presence of either dipole-dipole or ion-dipole type of interaction between the oxidant and the substrate (Fig. 3). Plot of $\log k_{1}$ versus (D $1) /(2 D+1)$ is a curvature indicating the absence of dipole - dipole interaction in the rate determining step. Amis (1967) holds the view that there is a possibility of a positive ionic reactant, as the rate decreases with the increasing dielectric constant of the medium ${ }^{23}$.

\section{Activation parameters}

The kinetics of oxidation of $2-\ln A$ was studied at four different temperatures viz., 298, 303, 308 and $313 \mathrm{~K}$. The second order rate constants were calculated (Table 3). The Arrhenius plot of log $k_{2}$ versus $1 / T$ is found to be linear. The enthalpy of activation, entropy of activation and free energy of activation were calculated from $k_{2}$ at 298, 303, 308 and $313 \mathrm{~K}$ using the Eyring relationship by the method of least square and presented in Table 3. The entropy of activation is negative for $2-\ln A$.

\section{Mechanism of oxidation}

A mechanism leading to the formation of the free radicals is unlikely in view of the failure to induce polymerization of acrylonitrile and no effect of the radical scavenger on the reaction rate. Positive slope of $\log k_{1}$ versus 1/D plot indicates that the reaction involves a cation-dipole type of interaction in the rate determining step. It has been shown that aldehyde oxidation reactions proceeded ${ }^{26}$ via the hydrated form. Hence, a mechanism involving a direct hydrogen-transfer reaction between a free aldehyde and BIFC was very unlikely.

The close resemblance in the structures of aldehyde hydrates and alcohols would favor similar pathways in their oxidation processes. The oxidation of alcohols had demonstrated the ratedetermining decomposition of the protonated acid chromate ester ${ }^{27}$. In an analogous manner, the oxidation of aldehydes could be visualized as proceeding via the formation of a similar

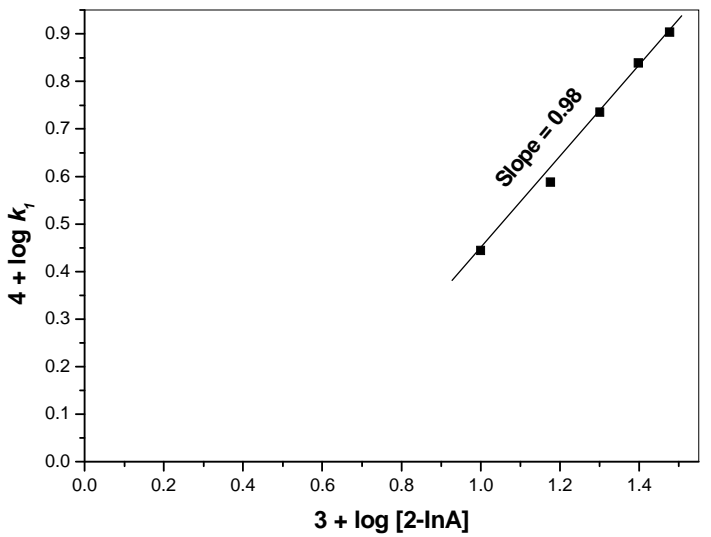

Fig . 1: Showing order plot of indole-2-aldehyde for the oxidation of indole -2-aldehyde by BIFC

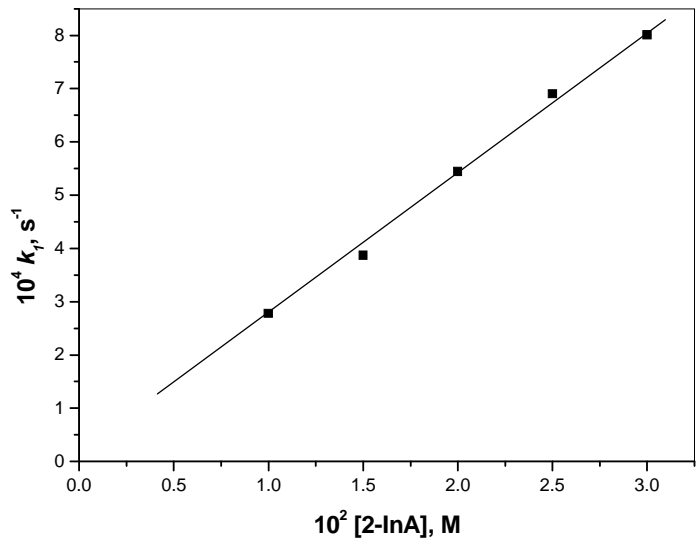

Fig. 2: Showing direct plot of indole-2-aldehyde for the oxidation of indole-2-aldehyde by BIFC

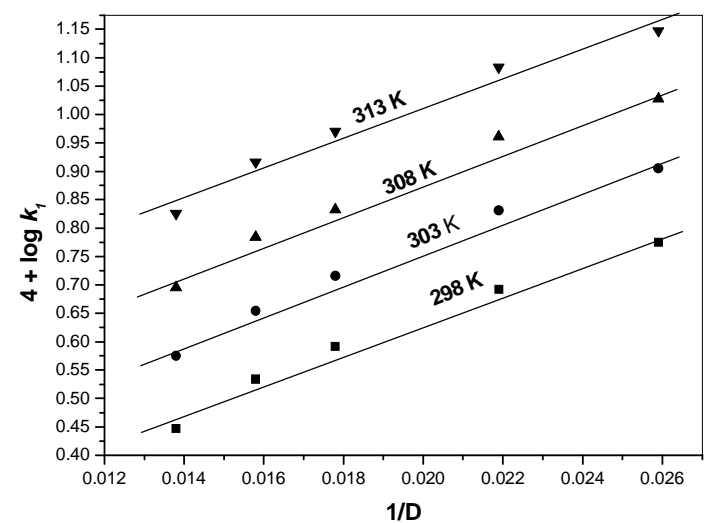

Fig . 3: Plot of 1 / D against $\log k_{\text {obs }}$ showing effect of solvent polarity for the oxidation of indole-2-aldehyde by BIFC at four different temperatures 
intermediate (an ester of the aldehyde hydrate). If the chromium was coordinated through the $-\mathrm{OH}$ group (of the aldehyde hydrate) in the cyclic transition state ${ }^{28}$ this would facilitate the formation of the chromate ester and enhance the ease of its oxidation to the corresponding carboxylic acid. Such a transition state envisaged the transfer of electrons towards the chromium, occurring by the formation of the carbon-hydrogen-oxygen bonds, as well as by the carbon-oxygen-chromium bonds.

The slow step of the reaction involved the participation of the aldehyde hydrate, protonated $\mathrm{BIFC}$, and two electrons in a cyclic system. Removal of the hydrogen (on the carbon) was part of this step. The sequence of reactions for the oxidation of 2-InA by $\mathrm{BIFCH}^{+}$, in acid medium (Scheme 1) showed that BIFC was converted to the protonated $\mathrm{BIFC}$ i.e., $\mathrm{BIFCH}^{+}$. The substrate (A) was converted to the hydrated form $(\mathrm{Hy})$, which reacted with $\mathrm{BIFCH}^{+}$, giving the monochromate ester intermediate $(E)$. The monochromate ester $(E)$ underwent decomposition, in the rate determining step, to give the product picolinic acid, along with the $\mathrm{Cr}(\mathrm{IV})$ species.

\section{Rate law}

The rate law has been derived as follows:

$-\mathrm{d}[\mathrm{BIFC}] / \mathrm{dt}=k_{3}[\mathrm{E}]=\mathrm{k}_{3}[\mathrm{Hy}]\left[\mathrm{BIFCH}^{+}\right]$

where

$[\mathrm{Hy}]=k_{2}[\mathrm{~A}]\left[\mathrm{H}_{2} \mathrm{O}\right]$

substituting the values of $\left[\mathrm{BIFCH}^{+}\right]$and $[\mathrm{Hy}]$ in the above Eq. 5 (taking the activity of water to be unity), we obtain

$$
-\mathrm{d}[\mathrm{BIFC}] / \mathrm{dt}=k_{1} k_{2} k_{3}[\mathrm{~A}][\mathrm{BIFC}]\left[\mathrm{H}^{+}\right]
$$

indicating that reaction exhibited first-order dependence on the concentrations of each reactant (substrate, oxidant and acid)

\section{CONCLUSIONS}

The kinetics of oxidation of 2-InA has been investigated in aqueous acetic acid medium in the presence of perchloric acid by spectrophotometrically at $303 \mathrm{~K}$. The oxidation of 2InA by BIFC is first order each with respect to the [2InA], [BIFC] and $\left[\mathrm{H}^{+}\right]$. The oxidation is catalysed by perchloric acid. The lowering of dielectric constant of reaction medium increases the reaction rate significantly. The reaction does not show the polymerization, which indicates the absence of free radical intermediate in the oxidation.

\section{REFERENCES}

1. Hiran, B. L.; Khuntwal, J.; Malkani, R. K.; Singh, D. Arab. J. Chem. 2011, doi:10.1016/ j.arabjc.2011.05.017

2. Krishnasamy, K.; Devanathan, D.; Dharmaraja, J. Trans. Met. Chem. 2007, 32, 922-926

3. Fathimajeyanthi, G.; Vijayakumar, G.; Elango, K. P. J. Serb. Chem. Soc. 2002, 67, 803-811

4. Asghar, B. H.; Mansoor, S.S.; Malik, V. S. Eur. Chem. Bull. 2013, 2(8), 538-544

5. Pandurangan, A.; Murugesan, V. React. Kinet. Catal. Lett. 1995, 54, 173-180

6. Mathiyalagan, N.; Sridharan, R. Indian J. Chem. 2005, 44A, 2044-2047

7. Rai, K. K.; Kannaujia, R. K.; Rai, K.; Singh, S. Orient. J. Chem. 2013, 29(3), 1071-1078
8. Ghammami, S.; Sajadi, S. A. S. J. Serb. Chem. Soc. 2005, 70 (11), 1243-1248

9. Sadeghy, B.; Ghammami, S. Russ. J. Gen. Chem. 2005, 75, 1886 - 1888

10. Ghammamy, S.; Mehrani, K.; Afrand, H.; Javanshir, Z.; Rezaeibehbahani, G.; Moghimi, A.; Aghbolagh, Z. S. J. Chil. Chem. Soc. 2009, 54, 491 - 493

11. Koohestani, B.; Javanshir, Z.; Ghammamy, S.; Mehrani, K.; Afrand, H.; Saghatforoush, L. J. Mex. Chem. Soc. 2008, 52, 116 - 119

12. Zhang, H. Z.; Drewe, J.; Tseng, B.; Kasibhatla, S.; Cai, S. X. Bioorg. Med. Chem. 2004, 12, 3649-55

13. Chaubey, G. S.; Das, S.; Mahanti, M. K. Heterocyclic Commun. 2002, 8, 497-500 
14. Chaubey, G. S.; Das S, Mahanti M K, Bull. Chem. Soc. Japan. 2002, 75, 2215-2220

15. Chaubey, G. S.; Bansie, J. Phy. Org. Chem. 2004, 17, 83-87

16. Saunte, H.; Chaubey, G. S.; Mahanti, M. K. Croat. Chem. Acta. 2010, 83, 291-298

17. Sivamurugan, V.; Rajkumar, G. A.; Arabindoo, B.; Murugesan, V. Indian. J. Chem. 2005, 44A, 144-147

18. Dharmaraja, J.; Krishnasamy, K.; Shanmugam, M. E-J. Chem. 2008, 5, 754760

19. Mansoor, S. S. Asian. J. Chem. 2010, 22, 7591-7600

20. Mansoor, S. S.; Shafi, S. S. Arab. J. Chem. 2014, 7, 171-176
21. Mansoor, S. S.; Shafi, S. S. Arab. J. Chem. 2011, doi: 10.1016/j.arabjc.2011.07.004

22. Asghar, B. H.; Malik, V. S.; Mansoor, S. S. Arab. J. Chem. 2014, doi: org/10.1016/ j.arabjc.2014.10.047

23. Amis E S, Solvent Effects on Reaction Rates and Mechanisms. Academic Press, New York, 1967, 42

24. Medien, H. A. A. Z Naturforsch. 2003, 58b, 1201-1205

25. Rocek, J.; Westheimer, F.H.; Eschenmoser, A.; Moldovanyi, L.; Schreiber, J. Helv. Chim. Acta. 1962, 45, 2554-2567

26. Swain, C. G.; Bader, R. F. W.; Estene, R. M.; Griffin, R. N. J. Am. Chem. Soc. 1961, 83, 1951-1955 